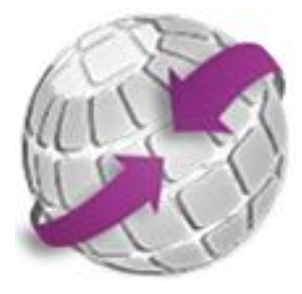

\title{
Asset Allocation in a Portfolio of Moroccan Mutual Funds: A First Investigation
}

\author{
Abdelhamid Hamidi Alaoui
}

Al Akhawayn University

\begin{abstract}
In Morocco, there are 72 mutual funds, called "Organisme de Placement Collectif en Valeurs Mobilières (OPCVM)". In December 2017, the value of these 72 mutual funds was over 400 billion Moroccan dirhams (more than 42 billion US dollars). Since holding a portfolio of mutual funds is be one of the less risky investments in any financial market, in this work, we test two simple methods in portfolio management on a portfolio of the 72 funds. The two methods asset allocation is based on are: 1) historical performance of the Sharpe ratio and 2) forecasting the rate of return using ARMA-GARCH $(1,1)$. We use daily data from February 01, 2012 to January 25, 2017 which we split into in-sample data (742 working days) and outof-sample data (495 working days). The in-sample data is used to build the scenarios of when to allocate assets based on method 1) or method 2) and when not to invest. The results show that we are 95\% sure that the portfolio's Sharpe ratio is higher than the average Sharpe ratio of the Moroccan mutual funds and that the portfolio's volatility is less than the average volatility of the funds.
\end{abstract}

Keywords: arma-garch, forecasting, portfolio management, opcvm, Sharpe ratio. 